\title{
Noradrenaline-Immunoreactive Neuronal Structures in the Cat Dorsal Vagal Complex: Interaction with Pargyline, Parachlorophenylalanine or Colchicine Pretreatment
}

\author{
Keiko Ikemoto ${ }^{1 *}$, Michael Geffard ${ }^{3}$, Yves Tillet ${ }^{4}$ and Kunio Kitahama ${ }^{2,5}$ \\ ${ }^{1}$ Department of Psychiatry, Iwaki Kyoritsu General Hospital, Iwaki, Fukushima, 973-8555, Japan, \\ 2Physiologie Integrative, Cellulaire et Moléculaire, UMR5123 CNRS/UCBL Lyon1. Bat Raphaël Dubois, Campus La Doua, 43 Bd du 11 Novembre 1918,69622 Villeurbanne \\ Cedex, France, \\ ${ }^{3}$ Laboratoire PIOM-EPHE, CNRS-UMR5501, Université Bordeaux I, France, \\ ${ }^{4}$ UMR6175, PRC INRA, Centre de Recherche de Nouzilly, 37380 Nouzilly, France \\ ${ }^{5}$ Sleep Disorders Research Team, Tokyo Institute of Psychiatry, Tokyo Metropolitan Organization for Medical Research, 2-1-8 Kamikitazawa, Setagaya-ku, Tokyo 156-8585, Japan
}

\begin{abstract}
We examined the localization and chemical nature of neurons immunoreactive to noradrenaline (NA) in the cat's dorsal vagal complex (DVC), using immunohistochemistry for NA, dopamine- $\beta$-hydroxylase (DBH), dopamine (DA) and tyrosine hydroxylase, under different conditions. In non-treated animals, localization of NA-immunoreactive (-ir) and DBH-ir neurons extensively overlapped. They were found mainly in the caudal portion of the nucleus of the solitary tract (NTS), and a small number in the dorsal motor nucleus of the vagus. Most were restricted to the commissural and ventral sub nuclei of the NTS. In the area postrema, we observed a small number of weakly stained NA-ir cell bodies alongside numerous intensely stained DBH-ir ones. Injection of the monoamine oxidase inhibitor (MAOI), pargyline, enhanced NA immunoreactivity in cells and axons of the DVC and increased their number. Treatment with MAOI plus parachlorophenylalanine, an inhibitor of tryptophan and phenylalanine hydroxylases, dramatically decreased both DA and NA immunoreactivities in a large number of axons, although NA immunoreactivity in cell bodies of the DVC remained visible. Treatment with Colchicine+MAOI intensified NA immunoreactivity exclusively in cell bodies in areas described above and where immunoreactivity to NA and DBH was weak and/or undetectable. The physiological implications were discussed referring to the previous reports.
\end{abstract}

Keywords: Dopamine; Nucleus of the solitary tract; Dorsal motor nucleus of the vagus; Noradrenaline; Dopamine- $\beta$-hydroxylase

Abbreviations: 5-HT: 5-Hydroxytryptamine; 5MT: Tract Of The Mesencephalic Trigeminal Nucleus; 5SP: Spinal Trigeminal Nucleus; 6-OHDA: 6-Hydroxydopamine; 12N: Hypoglossal Nucleus; A1A14, A1-A14 Catecholaminergic Cell Groups; AADC: Aromatic L-Aminoacid Decarboxylase; Ach: Acetylcholine; AP: Area Postrema; BC: Brachium Comjunctivum; C1-C2: C1-C2 Adrenergic Cell Groups; CA: Catecholamines; CC: Central Canal; COL: Colchicine; COM: Commissural Nucleus Of Cajal; DA: Dopamine; DBH: Dopamine-BHydroxylase; DMV: Dorsal Motor Nucleus Of The Vagus; DOPAC: 3,4-Dihydroxyphenylacetic Acid; DR: Dorsal Raphe Nucleus; DS: Dorsal Strip; DVC: Dorsal Vagal Complex; FTL: Lateral Tegmental Field; FTP: Pontine Tegmental Field; G: Glutaraldehyde; IO: Inferior Olive; ISC: Interstitiospinal Tract; LC: Locus Coeruleus Nucleus; L-DOPA: L-3,4-Dihydroxyphenylalanine; LRN: Lateral Reticular Nucleus; LSC: Locus Subcoeruleus; MAO: Monoamine Oxidase; MAOI: Monoamine Oxidase Inhibitor (Pargyline); Mnts: Medial Nucleus Of The Solitary Tract; NA: Noradrenlaine; NAT: Noradrenaline Transporter; PBL: Lateral Parabrachial Nucleus; PBM: Medial Parabrachial Nucleus; PCPA: DL-Parachlorophenylalanie; PD: Pyramidal Decussation; PEH: Periventricular Complex Of The Hypothalamus; PGO: Ponto-Geniculo-Occipital; PNMT: Phenylethanolamine N-Methyl Transferease; PY: Pyramidal Tract; PD: Pyramidal Decussation; REM: Rapid Eye Movements; RO: Raphe Obscurus Nucleus; RP: Raphe Pallidus Nucleus; SG: Substantia Gelatinosus; SN: Substantia Nigra; ST: Solitary Tract; SUB: Subpostrema Division Of The NTS; TH: Tyrosine Hydroxylase; VLM: Ventrolateral Meulla; VTA: Ventral Tegmental Area Of Tsai; VTB: Ventral Tegmental Bundle

\section{Introduction}

Lying in the dorsomedial medulla oblongata and consisting of the nucleus of the solitary tract (NTS), dorsal motor nucleus of the vagus (DMV), and area postrema (AP), the dorsal vagal complex (DVC) has a known involvement in autonomic functions such as cardiovascular, respiratory and visceral regulation. The DVC and ventrolateral medulla (VLM) play a major role in the central control of the cardiorespiratory and other parts of the autonomic nervous system. The NTS receives a variety of neurovegetative inputs from peripheral receptors and is crucially involved in integrating the information arising from the bronchopulmonary and arterial baro- or chemoreceptors. Arising from airways and chemosensory fibers in the chemoreceptors of the peripheral artery, these fibers project to the caudomedial NTS in the commissural nucleus (COM) close to the central canal $[1,2]$.

Structures of the DVC contain noradrenaline (NA) [3], as well as their synthesizing enzymes; tyrosine hydroxylase (TH) necessary for the production of L-dihydroxyphenylalanine (L-DOPA) from plasma L-tyrosine, aromatic L-amino acid decarboxylase (AADC) to convert L-DOPA to dopamine (DA), dopamine- $\beta$-hydroxylase (DBH) to catalyze the transformation of DA to NA. In fact, many neurons and

*Corresponding author: Keiko Ikemoto, Department of Neuropsychiatry, Fukushima Medical University, School of Medicine, 1 Hikarigaoka, Fukushima 960-1295, Japan. E-mail: ikemoto@fmu.ac.jp

Received December 09, 2014; Accepted November 26, 2015; Published December 08, 2015

Citation: Ikemoto K, Geffard M, Tillet Y, Kitahama K (2015) NoradrenalineImmunoreactive Neuronal Structures in the Cat Dorsal Vagal Complex: Interaction with Pargyline, Parachlorophenylalanine or Colchicine Pretreatment. J Neurol Neurophysiol 6: 334. doi:10.4172/2155-9562.1000334

Copyright: $\odot 2015$ lkemoto $\mathrm{K}$, et al. This is an open-access article distributed under the terms of the Creative Commons Attribution License, which permits unrestricted use, distribution, and reproduction in any medium, provided the original author and source are credited. 
Citation: Ikemoto K, Geffard M, Tillet Y, Kitahama K (2015) Noradrenaline-Immunoreactive Neuronal Structures in the Cat Dorsal Vagal Complex: Interaction with Pargyline, Parachlorophenylalanine or Colchicine Pretreatment. J Neurol Neurophysiol 6: 334. doi:10.4172/21559562.1000334

axons in the DVC show immunoreactivity to TH, AADC or DBH [4-9], and some contain all three enzymes. In addition, the DVC also contains the NA transporter (NAT), taking up NA into the presynaptic terminals once released into the synaptic cleft [10], and type A monoamine oxidase (MAO-A), a degrading enzyme which oxidizes NA and inactivates it [8].

We have previously described the distribution of DBH-ir cells in the human medulla oblongata using anti-human DBH [9]. In the human, $\mathrm{DBH}$-ir cells could be seen caudally in the COM and medial subnucleus of the NTS (mNTS), and extending more rostrally in the DVC beyond the AP. In the cat, we found some intensely labeled cells intermingled with many weakly stained ones, more restricted to the caudal portion of the DVC, such as the COM, mNTS and ventral periphery of the DMV from levels P17 to P13 of the Horsley Clarke stereotaxic plane [6]. A study in the rat reported that some cells in the rostral part contained phenylethanolamine N-mthyltransferease (PNMT) and were seemingly adrenergic, and thus named the $\mathrm{C} 2$ cell group [11]. However, many cells in the caudal portion show no immunoreactivity to PNMT $[5,12,13]$, and thus were considered noradrenergic. Similar evidence for this has been confirmed in the cat, sheep and human [6,14-18] equally predicting the presence of NA, though no direct evidence has been provided.

Earlier studies reported the presence of catecholamine (CA) fluorescence in the DVC of the rat [19-21] and cat [22-25]. These fluorescent cells and axons were believed to be noradrenergic, with some dopaminergic components. These reports described very briefly the distribution of these dorsomedial medullary CA cell bodies and axons, probably due to their weak fluorescence which disappears rapidly by ultraviolet emission.

Nowadays, NA immunohistochemistry allows the detection of NA immunoreactivity in cell bodies and terminals in glutaraldehyde-fixed cerebral tissue [26,27]. Several previous studies reported the presence of this amine in the rat [28], monkey [29], and in the lower vertebrates $[30,31]$.

Here we examine the neuronal structures showing NA immunoreactivity in the cat DVC by immunohistochemistry using an anti-NA antiserum in comparison with DBH and, if necessary, DA and $\mathrm{TH}$ immunoreactivities in the cat. We also examine variations in NA concentration following individual treatments with saline, monoamine oxidase inhibitor (MAOI), parachlorophenylalanine (PCPA, inhibitor of 5-HTP and L-tyrosine syntheses to decrease cerebral monoamines) [32], and colchicine. We use MAOI to increase NA concentration by preventing degradation of NA in cells and axons, and colchicine to accumulate NA in cell bodies by blocking the removal of NA from cell bodies to axons via anterograde axonal transport [33]. The administration of MAOI and/or combined treatment with colchicine (colchicine+MAOI) ensured the detection of as many cells and axons showing NA immunoreactivity as possible.

\section{Materials and Methods}

Procedures involving animals and their care were conducted in accordance with national and international law and policy guidelines (French Decree No.87848). A minimum number of animals were used to achieve this study, and special attention was given to minimize animal suffering.

\section{Tissue preparation for NA and DA immunohistochemistry}

Seventeen cats weighing 3-5 kg were used in this study. They were divided into five groups: animals were untreated $(n=2)$ or treated intraperitoneally (i.p.) with saline $(n=3)$; treated with an inhibitor of MAO $(10 \mathrm{mg} / \mathrm{kg}$ of Pargyline i.p., Sigma) $(\mathrm{n}=4) 2 \mathrm{~h}$ before sacrifice. Four cats were treated with parachlorophenylalanine (PCPA, $400 \mathrm{mg} / \mathrm{kg}$, i.p., Sigma), and in 4 cats, colchicine treatment was performed under deep sodium pentobarbital anesthesia $(25 \mathrm{mg} / \mathrm{kg}$, i.v.) by intraventricular injection of $200 \mu \mathrm{g}$ of colchicine (Sigma) in saline vehicle $(20 \mu \mathrm{l})$ over 30 min. Animals treated with PCPA and those with colchicine were kept for 46 hours in their cage and received MAOI injection $(10 \mathrm{mg} / \mathrm{kg}$ of Pargyline i.p., Sigma) $2 \mathrm{~h}$ before sacrifice. Animals were anesthetized by intravenous injection with a lethal dose of sodium pentobarbital (more than $40 \mathrm{mg} / \mathrm{kg}$ ), and perfused through the ascending aorta with 1 liter of $0.01 \mathrm{M}$ phosphate-buffered saline (PBS, $\mathrm{pH}$ 7.4) followed by 1 liter of fixative containing $2 \%$ glutaraldehyde, $1 \%$ sodium metabisulfite, and $0.25 \%$ picric acid in $0.1 \mathrm{M} \mathrm{PB}$ (pH 7.4). Brains were removed and cut into several $5 \mathrm{~mm}$-thick blocks. Tissue blocks were postfixed in the same fixative for 8 hours, and rinsed for 3 days in PBS containing 15\% sucrose and $1 \%$ sodium metabisulfite. Brain sections were then cut in coronal planes using a cryostat $(25 \mu \mathrm{m})$ under the same conditions. Sections of brain tissue from differently treated animals were reduced by sodium borohydrate, thoroughly washed and stocked in PBS with $1 \%$ sodium metabisulfite and sodium azide.

\section{Tissue preparation for DBH and TH immunohistochemistry}

For DBH- and TH-immunohistochemistry, 15 animals weighing 3-5 kg were used. They were divided into three groups: animals were untreated $(n=2)$ or treated intraperitoneally (i.p.) with saline $(n=3)$. Five cats were treated with parachlorophenylalanine (PCPA, $400 \mathrm{mg} / \mathrm{kg}$, i.p., Sigma), and in 5 cats, colchicine treatment was performed under deep sodium pentobarbital anesthesia $(25 \mathrm{mg} / \mathrm{kg}$, i.v.) by intraventricular injection of $200 \mu \mathrm{g}$ of colchicine (Sigma) in saline vehicle (20 $\mu \mathrm{l})$ over 30 min. Animals treated with PCPA and those with colchicine were kept for 48 hours in their cage before sacrifice.

Animals were anesthetized by intravenous injection with a lethal dose of sodium pentobarbital (more than $40 \mathrm{mg} / \mathrm{kg}$ ), and perfused through the aorta with 1 liter of saline, followed by 1.5 liter of $0.1 \mathrm{M}$ phosphate buffer (PB) containing $4 \%$ paraformaldehyde (pH 7.4). The brains were removed and post fixed in the same fixative.

Brain sections were then cut in coronal planes using a cryostat (25 $\mu \mathrm{m})$ under the same conditions. Sections of brain tissue from differently treated animals were stocked in PBS with sodium azide.

\section{Immunohistochemical staining}

Brain sections fixed with glutaraldehyde were incubated with a polyclonal primary antibody directed against NA, or directed against DA $[26,27,34]$, diluted $1: 30,000$ in PBS containing $0.3 \%$ Triton X-100 at $4^{\circ} \mathrm{C}$ for 48 hours. Those fixed with paraformaldehyde (or if necessary, with glutaraldehyde) were incubated with a polyclonal primary antibody directed against either DBH [18] or TH [35], diluted 1:30,000 in PBS containing $0.3 \%$ Triton X-100 at $4^{\circ} \mathrm{C}$ for 48 hours. These were thoroughly washed in PBS and incubated in biotinylated rabbit or mouse IgG (Vector Laboratory, 1:1,000) for $12 \mathrm{~h}$ at $4^{\circ} \mathrm{C}$, and after several rinses with $\mathrm{PBS}$, finally incubated in avidin-biotin-peroxidase complex (Vector Laboratory, 1:1,000) for $1 \mathrm{~h}$ at room temperature. Peroxidase activity was then revealed, for 10 minutes, in $50 \mathrm{mM}$ Tris$\mathrm{HCl}$ buffer ( $\mathrm{pH} 7.6$ ) containing $0.0003 \% \mathrm{H} 2 \mathrm{O} 2,0.01 \%$ 3,3'-diaminobenzidine- $4 \mathrm{HCl}(\mathrm{DAB})$ and $1 \%$ nickel ammonium sulfate. The reaction was terminated by washes in a Tris saline rinse. Sections were floated onto Tris solution on slides coated with $0.1 \%$ chromogelatin. Mounted sections were dehydrated and cover slipped using Depex. Sections were traced on a camera lucida to accurately locate DA-ir structures. 
Citation: Ikemoto K, Geffard M, Tillet Y, Kitahama K (2015) Noradrenaline-Immunoreactive Neuronal Structures in the Cat Dorsal Vagal Complex: Interaction with Pargyline, Parachlorophenylalanine or Colchicine Pretreatment. J Neurol Neurophysiol 6: 334. doi:10.4172/21559562.1000334

Details of the production, characterization, and specificity of NA and DA antibodies have been described elsewhere [23,24], and are briefly summarized below.

Prior to immunization NA or DA was linked via glutaraldehyde (G) to polypeptide carrier molecules such as bovine serum albumin (BSA). After coupling, the double bonds were saturated using sodium borohydride, and the resulting immunogens were purified. Rabbits were immunized by injection of the BSA-conjugate. The amino group of lysine from $\mathrm{N}$-alpha-acetyl-L-Lysine $\mathrm{N}$-methylamine (ALM) which mimics the lysine residue locations in the polypeptides was linked via glutaraldehyde to the amino group of NA.

Specificity was quantitatively demonstrated using the titrated derivative [3H] NA-G-ALM, or [3H] DA-G-ALM and the CA conjugates. Competition experiments were carried out with RIA. For anti-NA, the best displacement was observed with NA-G-ALM itself, between $10-8$ and 10-7M, and DA-G-ALM was 15 times less well recognized, between 10-7 and 10-6M, than DA-G-ALM. For anti-DA, the best displacement was observed with DA-G-ALM itself, between 10-8 and 10-7M, and DA-G-ALM was 53 times less well recognized, between 10-6 and 10-5M, than NA-G-ALM. From the affinity constant and cross reactivity ratio data, octopamine-G-ALM and tyramine-GALM were not considered recognized. Immunostainings using the present antiseum have previously published in the rat for anti-NA $[27,28,36]$.

Specificity of the immunohistochemical reaction was verified in the cat brain tissue. No immunohistochemical reaction was observed when the anti-NA or anti-DA serum was omitted or replaced by non-immune rabbit serum. The staining for anti-NA or anti-DA was completely inhibited after preincubation with antigen NA-G-ALM at 10-5M, or DA-G-BSA at 10-5M, respectively. No staining was obtained in the 5-HT-containing cell bodies in the raphe nuclei.

Anti-DBH and anti-TH were obtained by immunizing rabbits with the enzyme purified from bovine adrenal medulla; its specificity and characteristics have been published elsewhere [18,35]. As a control of immunohistochemical staining, sections were processed as described above except that preabsorbed anti-sera with antigen, or nonimmune sera were used instead of specific antisera. No immunostaining was found. The atlas of Berman [37] as well as that of Loewy and Burton [38] was consulted for nomenclature and identification of anatomical and stereotaxic planes.

\section{Results}

\section{Specificities of antibodies}

We successfully stained noradrenergic neuronal structures by NA immunohistochemical methods, obtaining distinct images of cell bodies as well as their long dendritic arbors in all the regions studied. In addition, we clearly identified NA-ir fine varicose fibers in the brains of MAOI- (cf. Figures 1 and 3 ) and non- treated (cf. Figure 2) animals.

As presented in Figure 1A, treatment with MAOI enhanced NA immunoreactivity in cell bodies of the dorsal pontine tegmentum (A6 and A7 CA cell groups), including the locus coeruleus (LC), locus subcoeruleus (LSC), lateral parabrachial (PBL), and medial parabrachial nuclei (PBM). Dendrites and fine varicose fibers of the LC were distinctly immunostained by the present antibody anti-NA (Figure 1B), though we observed no immunostaining after incubation in the antibody preabsorbed by the antigen NA-G-ALM (Figure 1C). We detected either no, or if any, faint NA immunoreactivity in substantia nigra (SN) cells in non-treated animals. However, following injection of MAOI, this anti-NA antibody stained very weakly SN and ventral tegmental area (VTA) cell bodies (Figure 1D) showing very intense DA immunoreactivity (Figure $1 \mathrm{E}$ ). We observed no NA immunostaining (Figure 1F) in hypothalamic cells showing strong DA immunoreactivity (Figure $1 G$ ) even after MAOI treatment. DA immunoreactivity in the DVC was very weak in non-treated and slightly less weak in MAOI-treated animals (Figure $1 \mathrm{H}$ ), whereas we found intense NA immunoreactivity in this same structure (Figures $1 \mathrm{~K}$, and cf.3E). Anti-NA distinctly stained NA-ir cells even after a dramatic decrease in DA concentration in this region by parachlorophenylalanine (PCPA) administration (cf. Figuer.4). The anti-DA antibody stained no AP cells which showed strong NA immunoreactivity after treatment with colchicine and MAOI (cf. Figure 5A, C). In all, the present antiNA antibody did not recognize DA immunoreactivity in the DVC of non-, MAOI-, or PCPA+MAOI- treated animals; nor did the anti-DA recognize NA immunoreactivity.

\section{Topographical distribution}

Medullary A1 and A2 cell groups were also distinctly labeled. Figures 1I to $1 O$ present photomicrographs in lower magnification of the sections of the medulla oblongata, stained by anti-NA in MAOI-treated animals, in caudorostral order from P17 to P10.5 of Horsley-Clark stereotaxic planes [37] for a better comprehension of topographical NA-ir structures. We observed the densest labeling restricted to the DVC, including the NTS, DMV and the AP. Ventrolaterally, NA-ir cell bodies (belonging to the Al cell group) were dispersed and sometimes aggregated in the lateral tegmental field (FTL) as shown in the inset of Figure 1L.

We observed dense networks of the NA-ir fibers in the hypoglossal, raphe pallidus nuclei and the inferior olive, as well as thick varicose axons in the ventral tegmental bundle (VTB) running through the dorsal medullary tegmentum. In all parts of the medulla oblongata we saw an uneven distribution of many fine varicose fibers, but not in the major myelinated axon bundles such as the pyramidal and spinocerebellar tracts.

\section{NA versus DBH immunoreactivity in non-treated animals (Figure 2)}

We observed a small number of NA-ir cell bodies, oval or fusiform in shape and $8 \times 9-10 \times 15 \mu \mathrm{m}$ in size located caudally at the P17 level (Figure 2A). These were distributed in a similar manner to $\mathrm{DBH}$-ir cell bodies (Figure $2 \mathrm{~B}$ ) in the medial NTS (mNTS) extending medially to the solitary tract (ST) and also in the DMV. At the same level, we also saw moderately dense NA-ir fibers in this region (indicated in a square) and in the commissural nucleus of Cajal (COM, subnucleus of the NTS) where they were few in number, though loosely aggregated around the central canal in a more caudal portion (not shown).

Slightly rostrally at the P13 level and as presented in Figure 2C, although observing numerous NA-ir varicose fibers in the medial portion of the mNTS (see also Figure 2E) and the ventrolateral periphery of the DMV (Figure $2 \mathrm{G}$ ), we found only a few small-sized oval or fusiformshaped NA-ir cell bodies $(8 \times 10-10 \times 20 \mu \mathrm{m})$ in the ventrolateral and lateral portions of the mNTS, and occasional medium-sized ones in the lateral mNTS (Figure $2 \mathrm{~F}$ ) and ventral periphery of the DMV. In contrast and as shown in Figure 2D, small to medium-sized DBH-ir neurons, morphologically similar to NA-ir ones, were extensively distributed in the dorsal mNTS, the subpostrema region (SUB) ventral to the AP (also Figure 2I), the center of the mNTS and the ventral periphery of the 


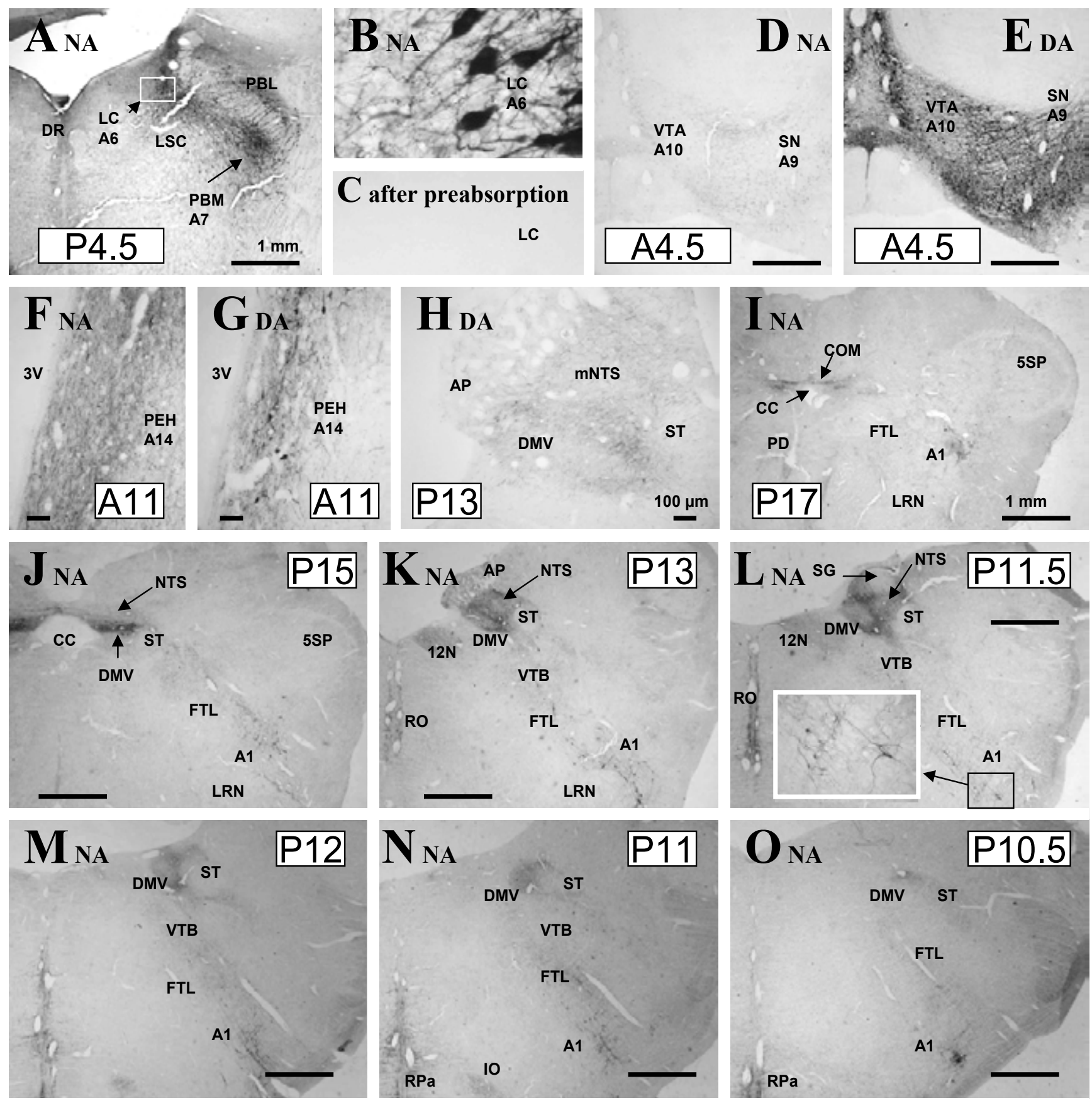

Figure 1: Specificity and Topography NA immunohistochemistry after MAOI treatment.

DMV (also Figure 2J). NA-ir axons were evident in the medial part of the mNTS (Figure 2H,I,J) and DMV. Although the AP itself contained small DBH-ir cells, only a few were immunoreactive to NA (indicated by an arrow in a rectangle, Figure 2C). In the substantia gelatinosus (SG, parvocellular subdivision of the NTS), we found small numbers of NA-ir fibers, but no labeled cell bodies.

At the P10.5 level (Figure $2 \mathrm{~K}$ ), we found densely concentrated NAir fibers in the ventrolateral periphery of the DMV, with more moderate dispersion in the dorsal and dorsomedial portions of the mNTS, and less in number in the lateral portion just medial to the ST. A few NA-ir cell bodies could be seen in the ventrolateral periphery of the DMV, and occasionally in the mNTS. As shown in Figure 2L, DBH-ir fibers presented a very similar distribution to NA-ir ones. We saw a small number of stained cells in the ventrolateral periphery of the DMV, and occasional ones in the dorsomedial part of the mNTS.

At the P11.5 level, we detected no NA-ir neurons in the mNTS or DMV, which contained a moderate density of stained fibers (Figure $2 \mathrm{~N})$. DBH-ir fibers presented a very similar distribution pattern to NAir ones (Figure 2O). In the medial portion of the DMV at this level, we noted DBH-ir punctuated structures, non immunoreactive to NA. 
Citation: Ikemoto K, Geffard M, Tillet Y, Kitahama K (2015) Noradrenaline-Immunoreactive Neuronal Structures in the Cat Dorsal Vagal Complex: Interaction with Pargyline, Parachlorophenylalanine or Colchicine Pretreatment. J Neurol Neurophysiol 6: 334. doi:10.4172/21559562.1000334
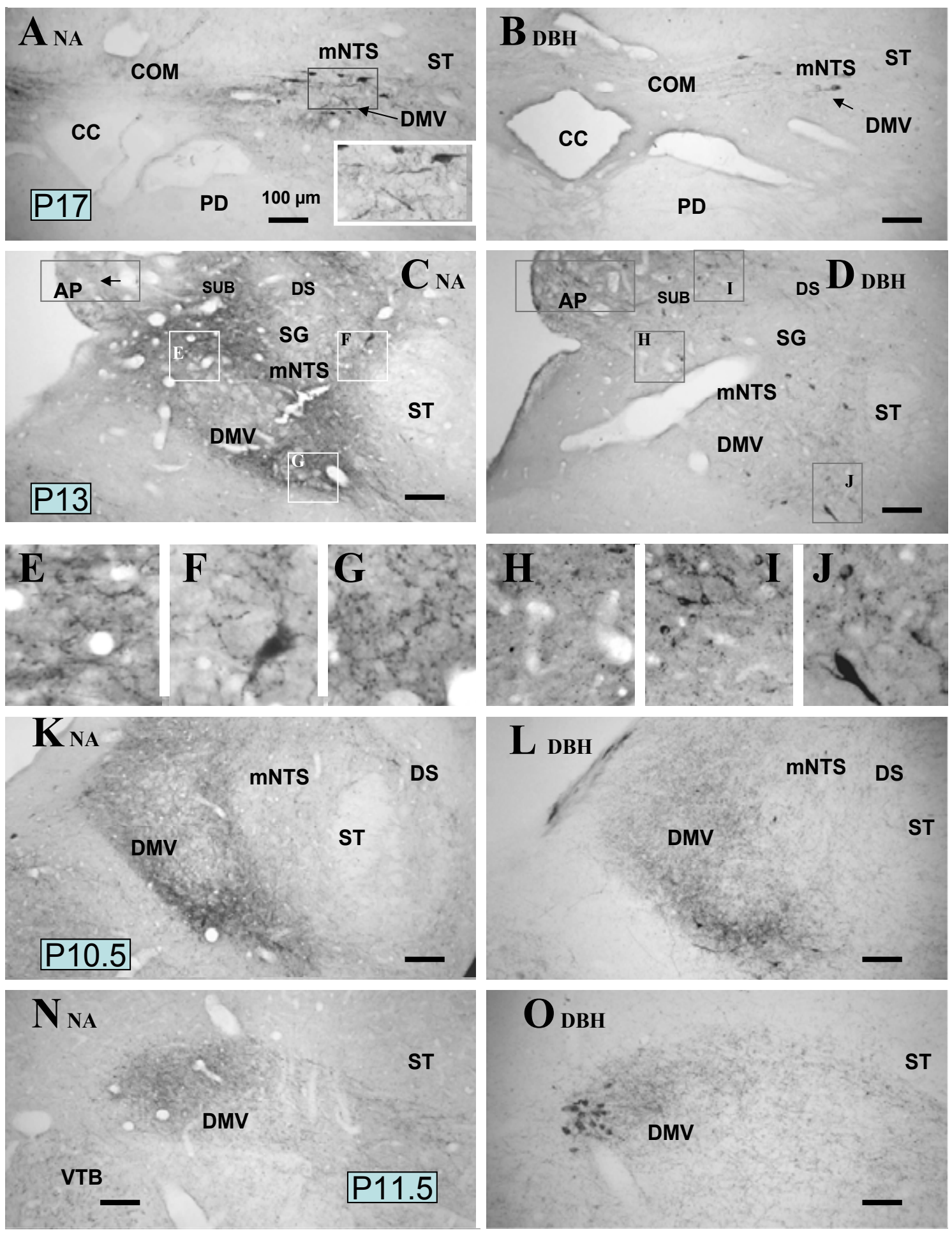

\section{$\mathbf{O}_{\text {рвн }}$}

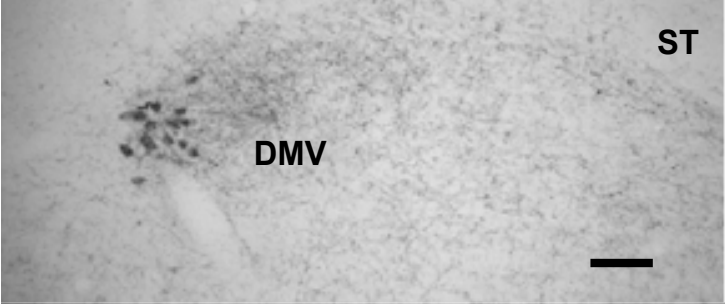

Figure 2: NA vs DBH in control animal .

\section{In MAOI-treated animals (Figure 3)}

Immunoreactivity to NA in cells and axons was enhanced. This treatment thus made it possible to clearly distinguish NA-ir cell bodies in regions where $\mathrm{DBH}$-ir cells are present though previously undetectable.
Caudally, we found some small NA-ir cells distributed in the COM and DMV (Figure 3A) as well as NA-ir axons more densely packed than those seen in non-treated animals (cf. Figure 2A). NA-ir axons approached and intersected small blood vessels, either arterioles or venules, and frequently climbed along or encircled these vessels (as indicated in a square or by arrows in Figure 3B) (also see Figure 3I). 
Citation: Ikemoto K, Geffard M, Tillet Y, Kitahama K (2015) Noradrenaline-Immunoreactive Neuronal Structures in the Cat Dorsal Vagal Complex: Interaction with Pargyline, Parachlorophenylalanine or Colchicine Pretreatment. J Neurol Neurophysiol 6: 334. doi:10.4172/21559562.1000334
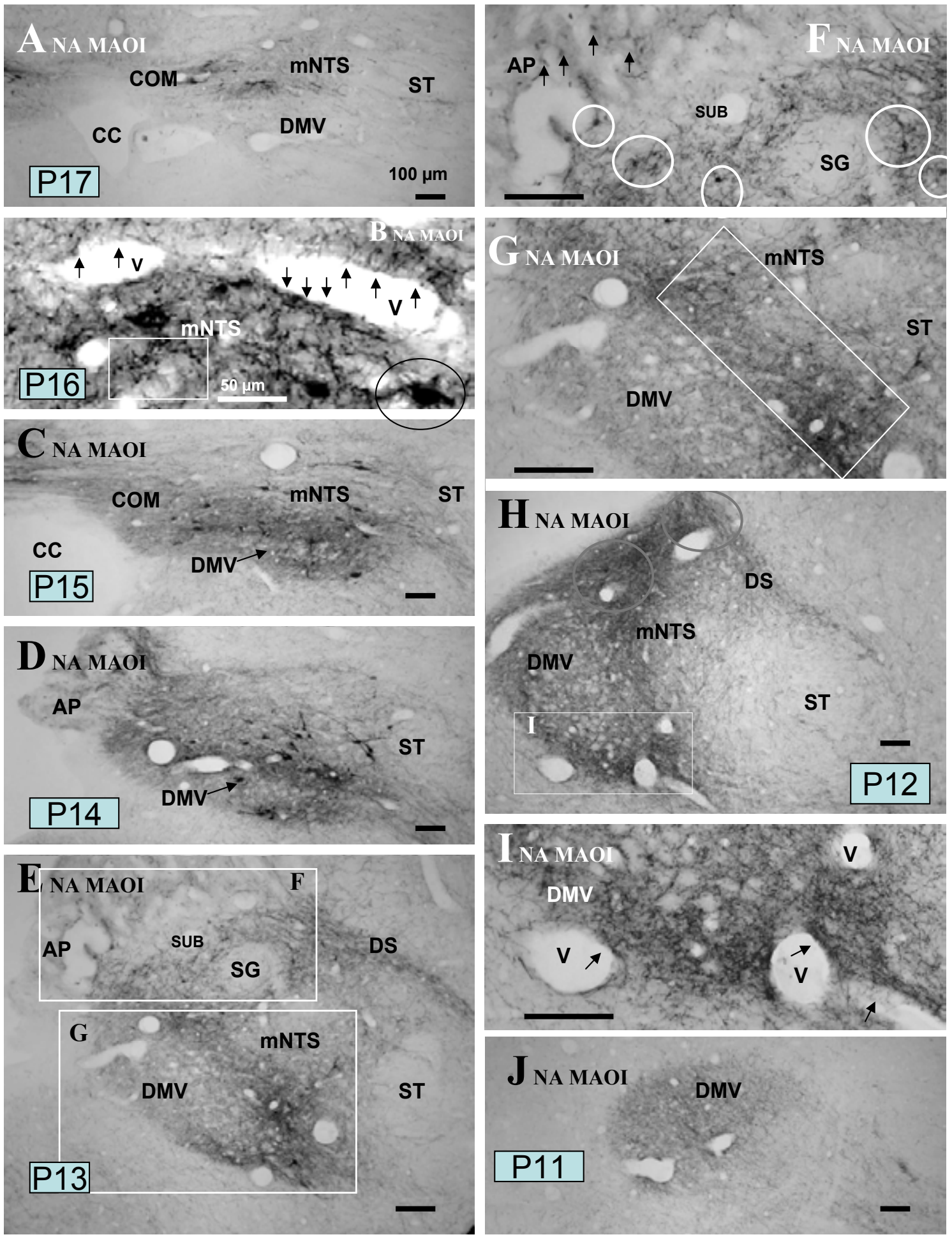

Figure 3: Effects of MAOI.

More rostrally, at the P15 level (Figure 3C), a horizontally elongated dense innervation of NA-ir varicose fibers in the mNTS extended more medially to the COM. NA-ir cell bodies could be clearly seen in the mNTS, mainly dorsal to the DMV, as well as in the COM and ventrally to and within the DMV. Slightly rostrally at the P14 level (Figure 3D), we observed densely innervated NA-ir varicose axons in the DVC, especially in the ventral portion of the mNTS and lateral periphery of the DMV. We detected an aggregation of medium-sized NA-ir cells mainly in the ventrolateral portion of the mNTS with small ones in its medial part.

At the level of the AP (P13 level) (Figure 3E), NA-ir fibers were 
Citation: Ikemoto K, Geffard M, Tillet Y, Kitahama K (2015) Noradrenaline-Immunoreactive Neuronal Structures in the Cat Dorsal Vagal Complex: Interaction with Pargyline, Parachlorophenylalanine or Colchicine Pretreatment. J Neurol Neurophysiol 6: 334. doi:10.4172/21559562.1000334

Page 7 of 15

densely innervated in the ventrolateral periphery of the DMV, around the Substantia Gelatinosa (SG) containing only a small number of stained axons, and in the dorsal strip (DS) of the NTS. We found numerous weakly stained small NA-ir cells in the AP as indicated by arrows in Figure 3F. In the SUB ventral to the AP with small DBH-ir cells, we found only a small number of NA-ir cells as indicated in circles
(Figure 3F). On the other hand, moderately stained NA-ir cells were observable in the mNTS dorsal to the DMV as indicated in a rectangle (Figure 3G).

At the P12 level (Figure 3H), we detected intensely stained NA-ir cells in the dorsal and dorsomedial portions of the mNTS (indicated

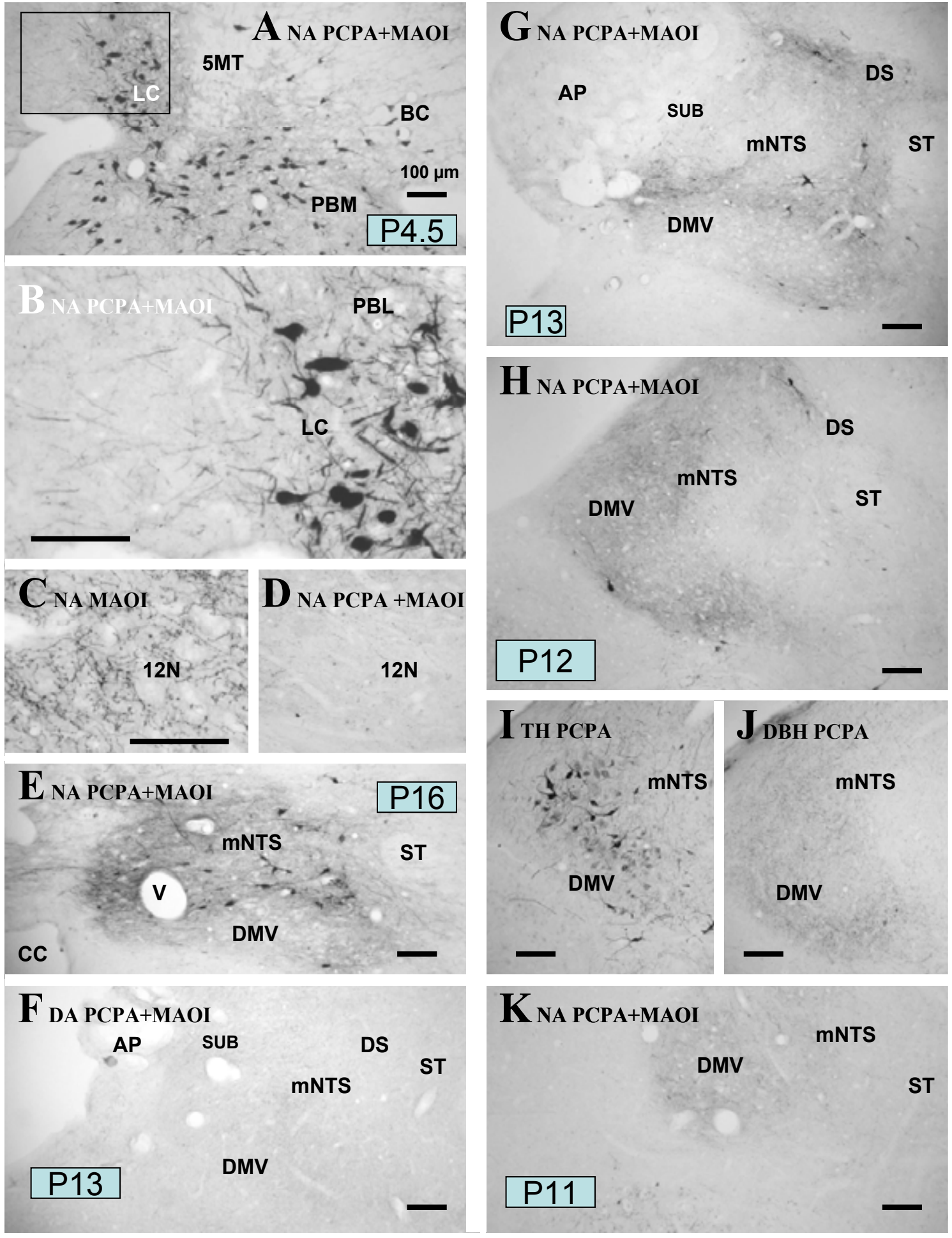

Figure 4: Effects of PCPA+MAOI. 
Citation: Ikemoto K, Geffard M, Tillet Y, Kitahama K (2015) Noradrenaline-Immunoreactive Neuronal Structures in the Cat Dorsal Vagal Complex: Interaction with Pargyline, Parachlorophenylalanine or Colchicine Pretreatment. J Neurol Neurophysiol 6: 334. doi:10.4172/21559562.1000334

in circles), and the ventrolateral periphery of the DMV. We observed a fairly dense NA-ir fiber plexus in the dorsomedial portion of the mNTS (cf. Figure 2K) and in the DMV.

Figure 3I (indicated in a square in Figure $3 \mathrm{H}$ ) presents higher magnification of NA-ir fiber innervation in the ventral DMV containing a large number of medium-sized NA-negative cell bodies, presumably cholinergic. NA-ir fibers were packed within the wall of the capillaries, and frequently climbed along or encircled these vessels (indicated by arrows in Figure 3I). NA-ir axons seemed in contact with the capillary walls throughout the rostrocaudal extent of the DVC (i.e.Figure 3A-J). More rostrally (Figure 3J), no or if any very occasional NA-ir cell bodies were distinguishable in the DMV containing a dense NA-ir fiber plexus.

\section{In PCPA+MAOI- treated animals (Figure 4)}

We noticed a general weakening in intensity of NA immunoreactivity in a dramatically decreased number of axons in all regions studied. However, in contrast to the reduced labeled axon plexi, we observed no decrease in immunoreactivity in cell bodies.

As a reference, we present here NA-ir structures in the dorsal pontine tegmentum (Figure 4A, B) after PCPA+MAOI treatment. We noted a reduction in the number of stained axons (cf. Figure 1B), though cell bodies of the A6 and A7 CA groups showed distinct NA immunoreactivity (cf. Figure 1A). Compared with those in control animals treated only with MAOI (Figure 4C), NA-ir axons decreased dramatically in number (Figure 4D) in the hypoglossal nucleus, in the medial vicinity of the DVC (cf. Figure $1 \mathrm{~K}, \mathrm{~L}$ ). In the caudal DVC (Figure 4E) at the level of the obex, NA-ir axons decreased in number in the DMV, although substantial numbers remained in the mNTS (cf. Figure 4D).

As a reference we have included Figure $4 \mathrm{~F}$ showing a decrease in intensity of DA immunoreactivity in the DVC at the P13 level following PCPA treatment. We observed no immunoreactivity to DA in cells and only a few DA-ir axons, whereas in MAOI- treated animals, we detected some weakly stained DA-ir cells and numerous labeled axons (cf. Figure $1 \mathrm{H})$.

At the same level (Figure 4G), NA immunoreactivity remained in axons within limited regions, such as the ventrolateral and dorsal parts of the mNTS as well as the ventral border (cf. Figure 3E). Although smaller in number, we could clearly see the NA-ir cell bodies in a similar manner to those in MAOI-treated animals. Those in the AP were too weakly stained to detect.

More rostrally, at the P12 level (Figure 4H), we saw a decrease in NA-ir axons in both the mNTS and the DMV. Although small number at this level we also detected NA-ir neurons in the DS and the ventral periphery of the DMV.

PCPA treatment made it possible to visualize TH immunoreactivity in many cells of the DMV, and DBH immunoreactivity in occasional cells. Figure 4I and J present examples at the P12 level. More rostrally at the P11 level, we detected no NA-ir cells in the rostral DMV and a weakened NA labeling in axons (Figure 4K).

\section{In colchicine+MAOI-treated animals (Figure 5)}

We noticed an increase in intensity of immunoreactivity to NA in cell bodies extending throughout the entire caudorostral extent of the DVC.

At the P13 level, as shown in Figure 5A, we observed a small number of labeled cells as distinctly aggregated in the dorsal portion (indicated in a rectangle $\mathrm{d}$ ) of the mNTS, extending medially in the SUB lying ventrolateral to the AP containing a large number of small intensely stained NA-ir neurons (square AP). These cells were packed in the ventral border of the mNTS (indicated in a rectangle E, also see Figure 5E), and some in an area ventrolateral to the DMV.

At the same level (Figure 5B), we observed intensely stained DBHir cell bodies in the dorsal portion (rectangle d) and the medial part of the mNTS as well as in the AP (square AP). However, as shown in rectangle $\mathrm{F}, \mathrm{DBH}$-ir cell bodies were difficult to detect in the ventral border of the mNTS (also see Figure 5F), and in the DMV.

As presented in Figure 5C, DA immunoreactivity became visible in DMV cell bodies as indicated in the circle. We detected stained cells in the dorsal and dorsolateral portions of the mNTS (rectangle d), although less in number in the ventral border of the mNTS (rectangle G, also see Figure 5G). The present anti-DA serum did not stain AP cells with a few exceptions (square AP).

TH-ir neurons (Figure 5D) were distributed in the whole extent of the AP (square AP) and DMV. We found TH immunoreactivity in numerous cells of the mNTS, including the dorsal (rectangle d) and dorsolateral portions surrounding the SG as well as the ventral border (rectangle $\mathrm{H}$, also see Figure $5 \mathrm{H}$ ).

Figure 5I presents a large number of intensely stained small NA-ir AP cells and subjacent SUB cells, with an identical distribution pattern to DBH-ir cells at the P12.5 level (Figure 5J). Finally, no or if any, occasional NA-ir cells could be seen in the more rostral portion of the DMV (Figure 5K) at the $\mathrm{P} 11$ level where $\mathrm{DBH}$-ir granular structures are present (cf.Figure 2O).

\section{Discussion}

\section{Specificities of Antibodies}

Using a polyclonal antibody raised against NA, the present study has provided the first detailed description of NA-ir neuronal structures in the cat DVC. Different pharmacological treatments were shown to differentially modify both NA immunoreactivity in cell bodies and the density of networks.

NA-ir structures have been described in lower vertebrates such as bony fish, amphibians and reptiles [30,31], with medullary NA-ir cells showing similar distribution patterns to DBH-ir cells. However no NA immunoreactivity has been observed in the $\mathrm{SN}$ of non-treated animals. In the present study in the cat, we observed no, or very faint staining of the SN cells in agreement with that reported in lower vertebrates.

No detailed description exists of NA-ir structures in mammals including the rat, except for some reports with several photomicrographs before and after administration of a neurotoxin, DSP-4 (N-(2chloroethyl)-N-ethyl-2-bromo enzylamine), which specifically destroys LC-originated NA axons $[28,39]$. One reason for the difficulty in using this antibody appears to be due to the weak cross reactivity with DA-G-ALM, when DA content increases in SN cells after MAOI treatment. In the present study, the specificity of this antibody was carefully examined by absorption tests, as well as by the comparison with DA-ir structures in the SN, hypothalamus, and other parts of the brain. According to cross-reactivity testing in vitro, this antibody recognizes DA-G-conjugate at the level of $1 / 15$ [26,27]. In the present study, it stained very weakly those SN neurons showing very intense DA immunoreactivity. However, it did not recognize hypothalamic neurons, which are moderately to intensely DA immunoreactive. The antibody stained very weakly striatal intense DA-ir terminals, but did 
Citation: Ikemoto K, Geffard M, Tillet Y, Kitahama K (2015) Noradrenaline-Immunoreactive Neuronal Structures in the Cat Dorsal Vagal Complex: Interaction with Pargyline, Parachlorophenylalanine or Colchicine Pretreatment. J Neurol Neurophysiol 6: 334. doi:10.4172/21559562.1000334
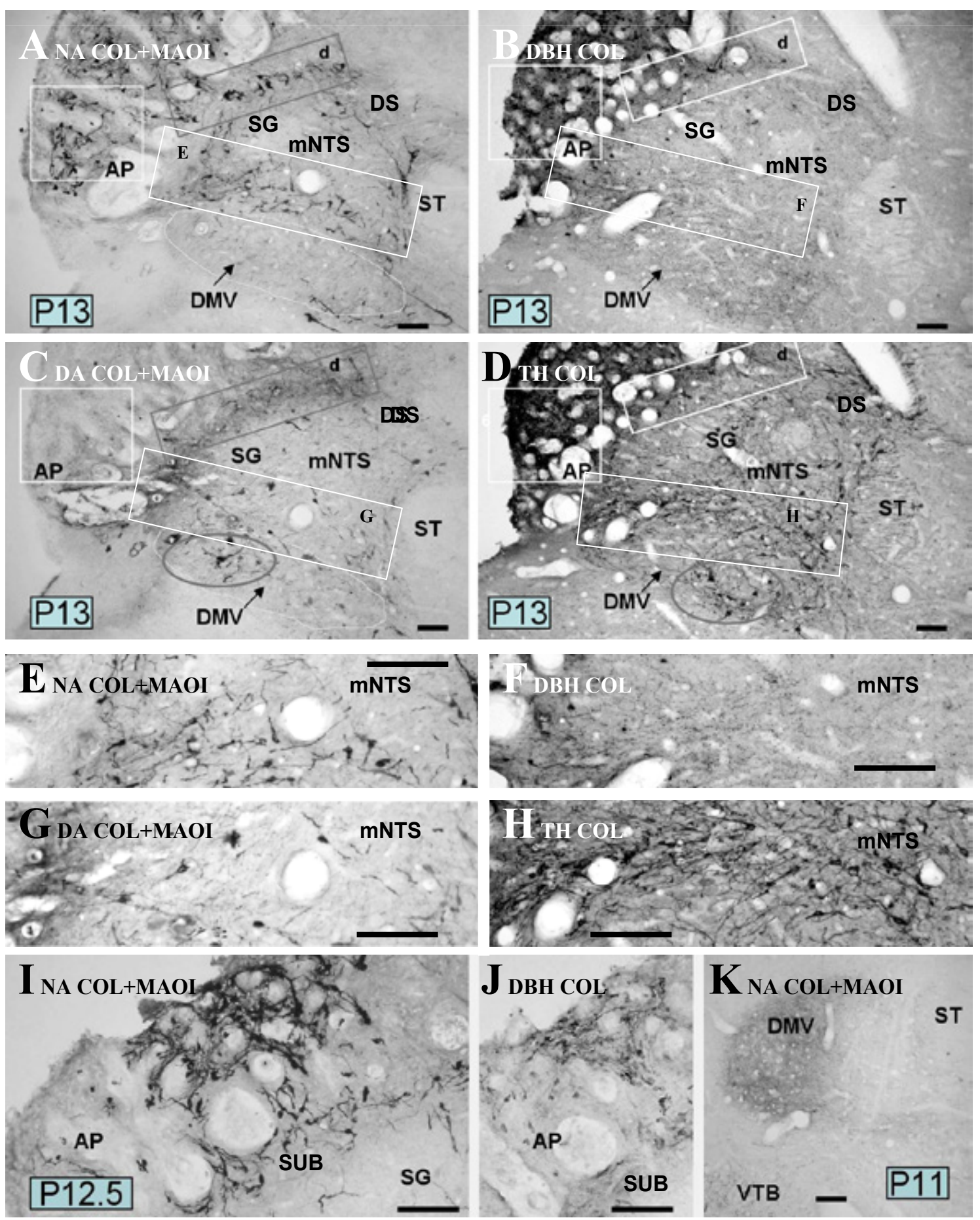

Figure 5: Effects of Colchicine+MAOI.

not stain DA-ir axons running in the nigrostriatal pathway. It stained clearly NA-ir cells even after a dramatic decrease in DA concentration caused by PCPA administration in this region. On the contrary, the present anti-DA did not stain NA-ir cells bodies, i.e. AP cells even after colchicine treatment. Taken together, these results demonstrate that it is safe to use this antibody to stain NA-ir cells and axons in the DVC, containing DA-ir fibers in weak to moderate intensity, and a small number of cells showing weak DA immunoreactivity.

\section{Comparison with previous CA histofluorescence studies}

In the present study, we observed weakly to moderately stained NAir cell bodies in the NTS mainly caudal to the obex, though also a few in a more rostral portion and some throughout the rostrocaudal extent of the DVC in non-treated animals. These results are consistent with previous studies $[22,25]$, and with that reported in the rat $[19,21]$ and $\operatorname{dog}[40]$. 
Citation: Ikemoto K, Geffard M, Tillet Y, Kitahama K (2015) Noradrenaline-Immunoreactive Neuronal Structures in the Cat Dorsal Vagal Complex: Interaction with Pargyline, Parachlorophenylalanine or Colchicine Pretreatment. J Neurol Neurophysiol 6: 334. doi:10.4172/21559562.1000334

Page 10 of 15

In the rat, previous investigations have reported that CA fluorescent cells are distributed mainly in the caudal portion of NTS, as the A2 CA cell group [19,21]. These were described as being restricted to the NTS and DMV caudal to the obex with non-identified in more rostral portions. In the cat homologous region, CA fluorescence studies have detected only a small number of positive neurons in the posterior part lying between the NTS and DMV, and rostrally in the ventrolateral periphery of the DMV $[22,23,25]$, although descriptions in these studies were focused mainly on the pontine structures and too simplified for the medullary ones. According to a more detailed description in the canine DVC, only a few CA fluorescent cells were seen in the NTS, with some throughout the rostrocaudal extent of the DMV [40].

With regards to CA fluorescent fibers, Jones and Friedman [23] demonstrated that the mNTS and DMV have the highest density of CA fluorescent fibers in the cat. Barnes et al. [40] presented photomontages of three levels of canine DVC and reported that a distinct band of fluorescent processes marked the dorsal border of the solitary tract with the gracile nucleus and a dense plexus in the lateral margin of the DMV. In this species, dense catecholamine histofluorescent fibers and varicosities are restricted to the mNTS and surround the DMV [20]. Our results are in accordance with this evidence that NA-ir fibers are observable in all parts of the DVC with uneven distribution. It appears that most of them are noradrenergic in nature judging from our results. The present study using NA immunohistochemistry has confirmed and extended these previous findings.

\section{Comparison with Data Obtained by Immunohistochemistry for DBH and for Other Synthesizing Enzymes}

Using another antibody in the present study, anti-bovine $\mathrm{DBH}$ [18], we obtained similar results to those previously reported [6]. It should be noted that, with some exceptions, DBH immunoreactivity was weak in many cell bodies of this region, though relatively intense in the A1 and LC cells. A moderately intense DBH immunoreactivity has been reported in the rat DVC $[5,13,41-43]$. Therefore, it appears that $\mathrm{DBH}$ protein level is low in the cat DVC region unlike that in the rat homologous region $[5,13]$. A slight increase in DBH immunoreactivity in somata following treatment with colchicine, which blocked axonal transport from the somata to axons, may suggest that $\mathrm{DBH}$ was slowly but constantly produced in the somata.

In the present study, we compared the distribution of $\mathrm{DBH}$ ir cells with that of NA-ir ones in the DVC, and confirmed essential similarities. However, in non-treated animals we noted fewer numbers of NA-ir cell bodies compared with DBH-ir ones in the AP, SUB, mNTS and the ventral periphery of the DMV. In contrast, these became much more numerous than DBH-ir cell bodies following MAOI and/or colchicine treatments to enhance NA immunoreactivity. This suggests that in these regions, small amounts of synthesized NA from the somata are released into the synaptic space and either taken up by the NA transporter (NAT) into the preterminal for oxidation by MAO, or rapidly removed to the axons. In addition, $\mathrm{DBH}$-ir granular structures in the rostral ventral DMV showed no immunoreactivity to NA even following MAOI+Colchicine treatment.

DA immunoreactivity in the DVC is very weak in cell bodies and axons in non-treated animals and weak even after MAOI-treatment. This may be due to the rapid conversion of DA to NA by DBH. In fact, inhibition of DBH activity by FLA63 increased DA immunoreactivity in the rat [44]. It should be noted here however, that in this region, cell bodies and axons showing immunoreactivity to $\mathrm{TH}$ but not to DBH have been reported in the rat [5,13] and human [9]. In the cat, according to Reiner and Vincent [17], TH-ir neurons far outnumbered $\mathrm{DBH}$-ir cells in the AP, with slightly greater numbers of $\mathrm{TH}$-ir cells seen in the COM, and uniquely TH-ir neurons seen within the DMV more caudal to the obex. We have examined this result in previous work, and identified immunoreactivity to AADC in many cell bodies of the cat DVC [7], with cells immunoreactive only to DA in the cat DMV [8] and in the NTS; though not in the AP, even after colchicine treatment (the present study). A detailed description of DA-ir cells will be presented in the next publication.

\section{Effects of MAOI}

It is well known that, in vitro and in vivo, NA is a specific substrate for type A MAO (MAO-A) present in the outer membrane of mitochondria [45-47]. Although mostly known as a specific inhibitor of type B MAO (MAO-B), pargyline also acts on MAO-A activity at high doses blocking the precipitation of oxidized product in NA cells [48]. In fact, i.p. injection of pargyline at $75 \mathrm{mg} / \mathrm{kg}$ has been shown to induce a $130-150 \%$ increase in DA and NA, respectively, and a $90 \%$ decrease in the DA metabolite DOPAC (3,4-dihydroxyphenylacetic acid) in the rat brain [49].

Once released into the intersynaptic space, NA is taken up by the NAT to the presynaptic structure where it is inactivated by MAO-A and catechol-O-methyltransferase (COMT). Pau et al. [50] described strong radiolabeling of NAT binding sites in cell bodies of the rabbit. The variation in density of binding sites seen using a selective ligand $[3 \mathrm{H}]$ nisoxetine to NAT in the monkey DVC [10] is quite similar to that of NA-ir axons in the DVC obtained after MAOI treatment in the present study. This confirms that in NA axons, NAT takes up NA into the presynaptic terminals for subsequent inactivation by MAO.

The present study has demonstrated that inhibition of MAO enhances NA immunoreactivity in DVC cells and axons, and consequently increased their number, especially rostral to the obex. We observed lightly stained NA-ir cells in the SUB and the ventral border of the mNTS, and more rostrally in the dorsal NTS. This suggests greater metabolic activity in rostral NA neurons compared to caudal ones under normal conditions.

Although the localization of COMT-containing structures in the DVC has not been elucidated, immunoreactivity to MAO-A has been reported as present in NTS cell bodies of the monkey and human $[51,52]$. We have previously demonstrated very strong MAO-A enzymatic activity in numerous DMV neurons of the cat $[53,54]$, though never in NTS neurons [46]. It remains to be demonstrated how NA is oxidized in such cell bodies.

On the other hand, NA immunoreactivity remained very weak in AP cells, even after MAOI treatment. This may be due to the removal of NA from the somata by anterograde axonal transport which we will discuss later in this manuscript.

\section{Effects of PCPA}

From a morphological viewpoint, it is interesting to note that after treatment with PCPA, NA immunoreactivity decreased dramatically or disappeared in axons even after MAOI treatment but remained sufficiently intense in cell bodies.

Firstly, the present study demonstrated as a reference, a dramatic disappearance of DA immunoreactivity in DVC cell bodies and axons, normally containing small amounts of DA. In fact, biochemical studies have reported a reduction in DA though levels of its metabolites remained constant after PCPA treatment [55]. We previously reported 
Citation: Ikemoto K, Geffard M, Tillet Y, Kitahama K (2015) Noradrenaline-Immunoreactive Neuronal Structures in the Cat Dorsal Vagal Complex: Interaction with Pargyline, Parachlorophenylalanine or Colchicine Pretreatment. J Neurol Neurophysiol 6: 334. doi:10.4172/21559562.1000334

that the intensity of immunoreaction (reflecting protein level) of $\mathrm{TH}$, the rate limiting enzyme for converting L-tyrosine to L-DOPA [56], increases after PCPA treatment, especially in DMV cells ([53] and the present study) to compensate for the decrease in DA. Under the same conditions, in the present study immunoreactivity to $\mathrm{DBH}$ remained unchanged, since $\mathrm{DBH}$ is not the rate limiting enzyme in the biosynthesis of NA. It is reasonable to suggest, therefore, that decreases in NA immunoreactivity in the brain may not be due to decreasing DBH enzymatic activity but rather to the deficiency of its precursor, DA. With DA no longer available for NA synthesis, this decrease in the precursors might induce a concomitant decrease in NA.

Previous biochemical studies have reported that PCPA induces a significant decrease (up to $90 \%$ ) in 5-HT and a slight decrease in NA (up to $20 \%$ ) in the whole brain [57]. This substance acts by inhibiting tryptophan and phenylalanine hydroxylases [32], and decreases concentrations of L-5-hydroxytryptophan (L-5-HTP) and L-tyrosine, and consequently those of 5-HT, L-DOPA, and DA.

With regards to levels of NA in cell bodies, the present results are consistent with previous biochemical studies on NA concentration in the brain. Biochemical assays have reported a decrease in NA limited only at $20 \% 2$ days after PCPA treatment as mentioned above. It appears that cells containing DBH as well as TH and AADC may take up decreased L-tyrosine from the blood circulation to synthesize NA.

However, a decrease in NA immunoreactivity in axons appears to be inconsistent with biochemical data indicating that central NA levels remain high to nearly $80 \%$ of control $[57,58]$. This discrepancy may be due to the difference in methods employed. Biochemical assays measure whole NA levels in cerebral tissues including circulating blood containing high levels of NA produced in the periphery due to incomplete L-tyrosine synthesis inhibition.

This fact may be due to much smaller amounts of vesicular NA storage in axons than in somata, and more rapid utilization than synthesis of NA from diminished L-tyrosine derived from the circulation. NA decrease after PCPA treatment has been shown as being accompanied by an increase in its metabolite, 3-methoxy-4hydroxyphenylglycol (MHPG), indicating an augmented utilization of this amine [55].

It is also possible that different levels of accumulated NA taken up into presynaptic terminals depend on NAT activity. In the brain stem, a strong radiolabeled density of the NAT selective ligand $[3 \mathrm{H}]$ nisoxetine has been observed in the LC (100\%), DMV (35\%) and NTS (21\%), attaining only $10-12 \%$ in the $12 \mathrm{~N}$ and IO, containing only NA axons [10].

It is known that NTS receives NA inputs from caudally located DVC $[4,21,43,59], \mathrm{AP}[60]$ and ventromedially located A1 cell region [61]. It should be noted in the present study that NA immunoreactivity in axons of the other parts of the medulla oblongata decreased in intensity and becoming either undetectable or very few in number in more distant axons. For example, those NA-ir axons forming a dense innervation in the hypoglossal nucleus originating from the A5 and A7 NA cell groups significantly decreased in number. NA-ir fibers also decreased in number in the inferior olive and raphe pallidus nucleus in which dense NA-ir fiber plexi are normally present. We noted an almost complete disappearance in more distant axons of the hypothalamus and limbic areas including the amygdaloid complex, to which parts of them are supplied from A2, A1 and A6 NA-ir cell bodies [62,63]. Based on these data, it is most likely that any remaining DVC NA-ir axons originate within the proximal NA-ir cell bodies mainly lying in the caudal DVC, as has been reported or suggested above by many authors $[4,21,43,59-61]$

In all, we can conclude that NA levels in somata remain relatively high even after PCPA treatment and even though a small amount of NA in axons is rapidly depleted.

\section{Effects of Colchicine}

We observed an accumulation of NA immunoreactivity in DVC cell bodies after colchicine+MAOI treatments, used to ensure the detection of as many cells and axons showing NA immunoreactivity as possible.

With regards to AP cells, no CA fluorescence With regards to AP cells, no CA fluorescence has been reported in the rat, rabbit, cat or dog $[19,22]$. In addition, we have failed to detect any DA immunoreactivity even after treatment with colchicine+MAOI in AP cells containing TH, AADC, DBH $[7,44]$ and GTP cyclohydrolase I (GCH, enzyme for synthesizing biopterin, a co-enzyme for $\mathrm{TH}$ ) [64], despite the prediction made by Kalia et al. $[5,13]$.

Although able to demonstrate here the presence of NA immunoreactivity in some AP cell bodies in non-treated and/or MAOItreated animals, we observed very weak or weak intensities respectively. However, intense immunoreactivity to NA became detectable in AP cells after treatment with MAOI+colchicine which blocks axonal transport thus leading to an accumulation of the substances in the originating cells. This evidence suggests a rapid removal of newly synthesized NA in the somata to axons projecting to for instance the NTS, parabrachial nucleus and the paraventricular hypothalamic nucleus [60].

The anterograde transportation of DBH and NA is now well established [33]. According to Levin [65], DBH and NA, primarily in particulate form, appear to be associated with fast axonal transport (24$48 \mathrm{~mm}$ /day) whereas $\mathrm{TH}$, predominantly in soluble form, with slow axonal transport (13-20 $\mathrm{mm} /$ day).

On the other hand, we cannot exclude the possibility that plasma NA taken up by AP cells is removed rapidly to the axons. Earlier studies reported the uptake of intraventricularly injected alpha-methyl-NA or radiolabeled NA into AP cells which have no brain blood barrier, indicating they have the capacity to take up NA [66-68]. Indeed, positive expression of radiolabeled NAT mRNA is very intense in rat and rabbit AP cell bodies [50,69]. AP cells maintained in vitro up to 6 $h$ with a retention of structural characteristics of viable tissue in a NA pool labeled with $[3 \mathrm{H}] \mathrm{NA}$, show an evoked stimulated release of $[3 \mathrm{H}]$ NA with $56 \mathrm{mM} \mathrm{K+}[70,71]$.

The NTS cells showed NA immunoreactivity after this treatment, especially in the dorsal portion, containing intense $\mathrm{DBH}$ immunoreactivity. On the other hand, the presence of intense NA immunoreactivity in very weakly stained DBH-ir cell bodies or DBHnegative cell bodies remains puzzling. One plausible explanation is that new NA, synthesized by a very small amount of DBH undetectable by our antiserum, accumulates in cell bodies over 48 hours after the treatment. In order to further elucidate on this, further studies will be necessary in the rat taking advantage of the intense DBH immunoreactivity in DVC cell bodies.

\section{Physiological Implication}

The NTS contains motor respiratory cells belonging to the dorsal respiratory group and contributes to the respiratory response to environmental challenges such as hypoxia [72]. The NTS region is connected by neural projections to the ventrolateral medulla (VLM), 
Citation: Ikemoto K, Geffard M, Tillet Y, Kitahama K (2015) Noradrenaline-Immunoreactive Neuronal Structures in the Cat Dorsal Vagal Complex: Interaction with Pargyline, Parachlorophenylalanine or Colchicine Pretreatment. J Neurol Neurophysiol 6: 334. doi:10.4172/21559562.1000334

Page 12 of 15

a region containing the motor neurons of the ventral respiratory group. The NTS A2C2 and VLM A1C1 CA cell groups are adjacent to, or intermingled with the respiratory neurons $[73,74]$. Although the respiratory neurons do not synthesize or store CA [74], they possess adrenergic receptors and receive close appositions from TH-ir neurons $[75,76]$.

We previously reported an increased NA turnover in the caudal part of A2 (caudal to the obex), remaining unaltered in the rostral part (rostral to the obex) of the rat exposed to hypoxia for 14 days [77]. In fact, under this condition, TH enzymatic activity and TH mRNA level increased in the caudal part after 7 days of hypoxia [78,79]. The delayed activation of TH suggests an involvement of A2 caudal NA cells in the central chemoreceptor pathway during long-term but not acute hypoxia.

Further quiescent noradrenergic cells in the NTS are recruited and participate in the overexpression of $\mathrm{TH}$ in this area [78]. The overexpression of $\mathrm{TH}$ protein correlates with increases in ventilatory output after acclimatization to hypoxia [80]. The major role played by noradrenergic neurons in the caudal NTS as neuromodulators of hypoxic ventilatory output is further underlined by their capacity to respond to hypoxia by expressing the transcription factor HIF-1a [81]. HIF-1a participates in the enhanced metabolic activity associated with the physiological responses to hypoxia [82] and, in particular, is capable of enhancing $\mathrm{TH}$ gene transcription [83].

In addition, the hypotensive drug dihydralazine induced a reverse effect, namely increased NA turnover in anterior A2 with no change in posterior A2 in normoxic rats [77]. The neurochemical responses to hypoxia were abolished by transaction of carotid sinus nerves. These results indicate that the caudal A2 group is influenced by peripheral chemosensory inputs, whereas the rostral one may be concerned with barosensitivity. They also suggest an increased sympathetic activation, possibly involved in the mediation of respiratory responses to hypoxia. On the other hand, 73 to $85 \%$ of NA cells expressed c-fos immunoreactivity following exposure of unanesthtized rats to hypercapnic stress for $60 \mathrm{~min}$ [84]

In the cat A2 region, without any treatment, NA is more concentrated in caudally located cell bodies than those more rostrally (the present study). NA may be utilized more in the caudal part than in the rostral part under long-term hypoxia, and consequently TH activity may be increased to maintain NA concentration.

On the other hand, NA in the NTS has known involvement in cardiovascular function. Intraventricularly injected NA decreases BP and heart rate [85]. Lesion of the NTS provokes hypertension [86,87] whereas electrical stimulation of the NTS causes hypotension and bradycardia [88]. The A2 region is the most sensitive to locally applied CA [89]. The NA release rate transiently diminishes during and after cat carotid occlusion [90]. NA neurons of the NTS receive impulses from baroreceptors of the carotid sinus and aortic arch [91]. Microinjection in situ of NA induces a dose-dependent decrease in blood pressure believed to be mediated by the alpha 2 receptor.

As mentioned above, the NTS at the level of the obex receives noradrenergic input from neurons originating within the more caudal DVC and AP, and ventromedially located Al cell region. The NTS also receives input from the nodose ganglion. Sumal et al. [92] reported wide distribution of vagal afferents autoradiographically labeled by $[3 \mathrm{H}]$ amino acids throughout the more caudal NTS TH-ir cell bodies. A2 $\mathrm{TH}$-ir cells were shown to express c-fos protein following unilateral electrical stimulation of abdominal vagal afferents [93]. NA neurons in the rat NTS participate in the esophageal-gastric relaxation reflex [94] Increase or decrease in DVC NA by MAOI or PCPA treatment as well as in situ microinjection of CA neurotoxin may clarify in more detail the physiological implication of DVC NA in autonomic regulations.

The NTS CA cells reportedly send their axons to the medullary autonomic brain regions parabrachial region, and to more distant areas such as the hypothalamus and amygdala $[38,95]$. The injection of cholecystokinin reduces rat supraoptic NA immunoreactivity in fibers originating exclusively within the A2 region, which expressed c-fos protein [96]. This indicates an increase in neuronal activity and NA production.

With regards to the DMV, we demonstrated here that in the cat, NA-ir cells are mainly restricted to the caudal portion of the DMV with some at the ventral periphery. Using double immunostaining of TH and DBH with the retrograde tracer Fluoro-Gold, Yang et al. [97] showed that the rat subdiaphragmatic vagal $\mathrm{CA}$ fibers originate within $\mathrm{TH}$-ir cells in the DMV (75\%), among which $12 \%$ are noradrenergic mainly lying in the caudal portion.

On the other hand, with regards to the rostral DMV, we observed densely innervated NA-ir axons seemingly in contact with mediumsized nonlabeled cell bodies sending to preganglionic parasympathetic nerve fibers, i.e. to the laryngeal, tracheobronchial, pulmonary, cardiac and gastrointestinal branches [98-100]. Many of these neurons are cholinergic [41] and a possible involvement of the noradrenergic innervation of DMV in direct synaptic inhibition of parasympathetic preganglionic neurons of the vagus has been considered as follows.

Radiolabeling the alpha2 binding site, using [3H] paraaminoclonidine, Unnerstall et al. [101] reported highest grain densities in the rat and human DMV (also [102]). The dense NA-ir fiber innervation in the DMV observed in the present study correlates well with these previous studies suggesting the possible existence of alpha2 NA receptors in DMV cholinergic cell bodies. As a result DMV cholinergic neurons modulating preganglionic regulation would be influenced by NA axons.

In the periphery, adrenergic inhibition could play a predominant role in decreasing acetylcholine (ACh) release. Akiyama and Yamazaki [103] demonstrated the adrenergic modulation of endogenous ACh release from vagal nerve terminals in the in vitro heart. Siaud et al. [104] investigated the effects of bilateral 6-hydroxydopamine (6-OHDA) lesions with adrenergic innervation of the DMV on pancreatic insulin secretion in normal and vagotomized rats. After two weeks the 6-OHDA lesions produced a marked increase in circulating insulin levels.

Finally, in the electrophysiological field, PCPA induces long lasting insomnia accompanied by Ponto-Geniculo-Occipital (PGO) waves, originating in the pons to activate thalamus and visual cortex. PGO waves occur normally during Rapid Eye Movement (REM) Sleep, equivalent to dream state in humans [105]. The production of REM sleep is generated by pontine and/or medullary cholinergic system [106] which is inhibited by 5-HT and NA neurons during waking and sleep. A decrease in these amines by PCPA disinhibits pontine and/ or medullary cholinergic mechanisms and induces PGO waves. The present results showing a decrease in NA immunoreactivity in axons, provide evidence to explain the induction of PGO waves after PCPA treatment which decreases dramatically NA and 5-HT in axons.

\section{Acknowledgments}

This work was supported by CNRS UMR5123 for K.K. and J.M.P, INSERM for M.G., INRA (Y.T.) and CNRS UMR5167 for K.O 
Citation: Ikemoto K, Geffard M, Tillet Y, Kitahama K (2015) Noradrenaline-Immunoreactive Neuronal Structures in the Cat Dorsal Vagal Complex: Interaction with Pargyline, Parachlorophenylalanine or Colchicine Pretreatment. J Neurol Neurophysiol 6: 334. doi:10.4172/21559562.1000334

Page 13 of 15

\section{References}

1. Bonham AC, McCrimmon DR (1990) Neurones in a discrete region of the nucleus tractus solitarius are required for the Breuer-Hering reflex in rat. J Physiol 427: 261-280.

2. Housley GD, Sinclair JD (1988) Localization by kainic acid lesions of neurones transmitting the carotid chemoreceptor stimulus for respiration in rat. J Physio 406: 99-114.

3. Versteeg DH, Van Der Gugten J, De Jong W, Palkovits M (1976) Regional concentrations of noradrenaline and dopamine in rat brain. Brain Res 113: 563 574

4. Hökfelt T, Johansson O, Fuxe K Goldstein M, Park D (1976) Immunohistochemical studies on the localization and distribution of monoamine neuron systems in the rat brain. I. Tyrosine hydroxylase in the mes- and diencephalon. Med Biol 54: 427-453.

5. Kalia M, Fuxe K, Goldstein M (1985a) Rat medulla oblongata. II. Dopaminergic noradrenergic (A1 and A2) and adrenergic neurons, nerve fibers, and presumptive terminal processes. J Comp Neurol 233: 308-332.

6. Kitahama K, Denoroy L, Bérod A, Jouvet M (1986) Distribution of PNMTimmunoreactive neurons in the cat medulla oblongata. Brain Res Bull 17: 197208.

7. Kitahama K, Denoyer M, Raynaud B, Borri-Voltattorni C, Weber M, et al. (1990b) Aromatic L-amino acid decarboxylase immunohistochemistry in the cat lower brainstem and midbrain. J Comp Neurol 302: 935-953.

8. Kitahama K, Buda C, Sastre JP, Nagatsu I, Raynaud B, et al. (1992) Dopaminergic neurons in the cat dorsal motor nucleus of the vagus, demonstrated by dopamine, AADC and TH immunohistochemistry. Neurosci Lett 146: 5-9.

9. Kitahama K, Sakamoto N, Jouvet A, Nagatsu I, Pearson J (1996) Dopaminebeta-hydroxylase neurons and fibers in human medulla oblongata and pons. $J$ Chem Neuroanat 10: 137-146.

10. Smith HR, Beveridge TJ, Porrino LJ (2006) Distribution of norepinephrine transporters in the non-human primate brain. Neuroscience 138: 703-714.

11. Hökfelt T, Johansson O, Goldstein, M (1974) Immunohistochemical evidence for the existence of adrenaline neurons in the rat brain. Brain Res 66: 235-251.

12. Armstrong DM, Ross CA, Pickel VM, Joh TH, Reis DJ (1982) Distribution of dopamine-, noradrenaline-, and adrenaline-containing cell bodies in the rat medulla oblongata: demonstrated by the immunocytochemical localization of catecholamine biosynthetic enzymes. J Comp Neurol 212: 173-187.

13. Kalia M, Fuxe K, Goldstein M (1985b) Rat medulla oblongata. III. Adrenergic (C1 and $\mathrm{C} 2$ ) neurons, nerve fibers and presumptive terminal processes. J Comp Neurol 233: 333-349.

14. Arango V, Ruggiero DA, Callaway JL, Anwar M, Mann JJ, et al. (1988) Catecholaminergic neurons in the ventrolateral medulla and nucleus of the solitary tract in the human. J Comp Neurol 273: 224-240.

15. Ikemoto K, Amano R, Ishibe A, Nishimura A, Nishi K, et al. (2000) Quantitative analysis of tyrosine hydroxylase, aromatic L-amino acid decarboxylase or phenylethanolamine- $\mathrm{N}$-methyltransferase-immunoreactive neurons in the human medullary C1 region. Acta Histochem Cytochem 33: 259-265.

16. Kitahama K, Pearson J, Denoroy L, Kopp N, Ulrich J, et al. (1985) Adrenergic neurons in the human brain demonstrated by immunohistochemistry with antibodies to phenylethanolamine N- methyltransferase (PNMT): Discovery of a new group in the nucleus tractus solitarius. Neurosci Lett 53: 303-308.

17. Reiner PB, Vincent SR (1986) The distribution of tyrosine hydroxylase, dopamine-beta-hydroxylase, and phenylethanolamine-N-methyltransferase immunoreactive neurons in the feline medulla oblongata. J Comp Neurol 248 $518-531$

18. Tillet Y, Thibault J (1989) Catecholamine-containing neurons in the sheep brainstem and diencephalon: Immunohistochemical study with tyrosine hydroxylase $(\mathrm{TH})$ and dopamine-ß-hydroxylase $(\mathrm{DBH})$ antibodies. J Comp Neurol 290: 69-104.

19. Dahlström A, Fuxe K (1964) Evidence for the existence of monoaminecontaining neurons in the central nervous system. I. Demonstration of monoamines in the cell bodies of the brain stem neurons. Acta Physiol Scand Suppl 62: 1-55

20. Koda LY, Bloom FE (1983) Distribution of catecholamine-containing cell bodies and blood vessels in the rat nucleus tractus solitarius. Brain Res 289: 71-78.
21. Levitt $P$, Moore RY (1979) Origin and organization of brainstem catecholamine innervation in the rat. J Comp Neurol 186: 505-528.

22. Blessing WW, Frost $P$, Furness JB (1980) Catecholamine cell groups of the cat medulla oblongata. Brain Res 192: 69-75.

23. Jones $B E$, Friedman $L$ (1983) Atlas of catecholamine perikarya, varicosities and pathways in the brain stem of the cat. J Comp Neurol 215: 382-396.

24. Poitras D, Parent A (1978) Atlas of the distribution of monoamine-containing nerve cell bodies in the brain stem of the cat. J Comp Neurol 179: 699-717.

25. Wiklund L, Leger L, Persson M (1981) Monoamine cell distribution in the cat brain stem. A fluorescence histochemical study with quantification of indolaminergic and locus coeruleus cell groups. J Comp Neurol 203: 613-647.

26. Geffard M, Henrich-Rock AM, Dulluc J, Seguela P (1985) Antisera against smal neurotransmitter-like molecules. Neurochem Int 7: 403-413.

27. Geffard M, Patel S, Dulluc J, RockAM (1986) Specific detection of noradrenaline in the rat brain by using antibodies. Brain Res 363: 395-400.

28. Fritschy JM, Geffard M, Grzanna R (1990) The response of noradrenergic axons to systemically administered DSP-4 in the rat: an immunohistochemical study using antibodies to noradrenaline and dopamine-ß-hydroxylase. J Chem Neuroanat 3: 309-321.

29. Ikemoto K, Kitahama K, Maeda T, Satoh K (1996) The distribution of noradrenaline, serotonin, and gamma-aminobutyric acid in the monkey nucleus accumbens. Prog. Neuropsychopharmacol. Biol Psychiatry 20: 1403-1412.

30. Meek J, Joosten HW, Hafmans TG (1993) Distribution of noradrenalineimmunoreactivity in the brain of the mormyrid teleost Gnathonemus petersii. Comp Neurol 328: 145-160.

31. Smeets WJ, Gonzalez A (2000) Catecholamine systems in the brain of vertebrates: new perspectives through a comparative approach. Brain Res Brain Res Rev 33: 308-379.

32. Koe BK, Weissman A (1966) p-Chlorophenylalanine: a specific depletor of brain serotonin. J Pharmacol Exp Ther 154: 499-516.

33. Dahlström AB, Czernik AJ, Li JY (1992) Organelles in fast axonal transport. What molecules do they carry in anterograde vs retrograde directions, as observed in mammalian systems? Mol Neurobiol 6: 157-177.

34. Kitahama K, Geffard M, Okamura H, Nagatsu I, Mons N, et al. (1990a) Dopamine- and DOPA-immunoreactive neurons in the cat forebrain with reference to tyrosine-hydroxylase-immunohistochemistry. Brain Res 518: 8394.

35. Nagatsu I, Kondo Y, Inagaki S, Karasawa N, Kato T, et al. (1977) Immunofluorescent studies on tyrosine hydroxylase: Application for its axoplasmic transport. Acta Histochem Cytochem 10: 494-499.

36. Seguela P, Watkins K, Geffard M, Decarries L (1990) Noradrenaline axon terminals in adult rat neocortex:an immunocytochemical analysis in serial thin sections. Neuroscience 35: 249-264.

37. Berman AL (1968) The Brain Stem of the Cat. A Cytoarchitectonic Atlas with Coordinates. University of Wisconsin Press, Madison.

38. Loewy AD, Burton $H$ (1978) Nuclei of the solitary tract: efferent projections to the lower brain stem and spinal cord of the cat. J Comp Neurol 181: 421-449.

39. Grzanna R, Berger U, Fritschy JM, Geffard M (1989) Acute action of DSP-4 on central norepinephrine axons: biochemical and immunohistochemical evidence for differential effects. J Histochem Cytochem 37: 1435-1442.

40. Barnes KL, Chernicky CL, Block CH, Ferrario CM (1988) Distribution of catecholaminergic neuronal systems in the canine medulla oblongata and pons. J Comp Neurol 274: 127-141.

41. Kimura H, McGeer PL, Peng JH, McGeer EG (1981) The central cholinergic system studied by choline acetyltransferase immunohistochemistry in the cat. J Comp Neurol 200: 151-201.

42. Ritchie TC, Westlund KN, Bowker RM, Coulter JD, Leonard RB (1982) The relationship of the medullary catecholamine containing neurones to the vagal motor nuclei. Neuroscience 7: 1471-1482.

43. Swanson LW, Hartman BK (1975) The central adrenergic system. An immunofluorescence study of the location of cell bodies and their efferen connections in the rat utilizing dopamine-beta-hydroxylase as a marker. $J$ Comp Neurol 163: 467-505. 
Citation: Ikemoto K, Geffard M, Tillet Y, Kitahama K (2015) Noradrenaline-Immunoreactive Neuronal Structures in the Cat Dorsal Vagal Complex: Interaction with Pargyline, Parachlorophenylalanine or Colchicine Pretreatment. J Neurol Neurophysiol 6: 334. doi:10.4172/21559562.1000334

Page 14 of 15

44. Kitahama K, Nagatsu I, Geffard M, Maeda T (2000) Distribution of dopamineimmunoreactive fibers in the rat brainstem. J Chem Neuroanat 18: 1-9.

45. Ikemoto K, Kitahama K, Maeda T, Tokunaga Y, Valatx JL, et al. (1997) Electronmicroscopic study of MAOB-containing structures in the nucleus accumbens shell: Using MAOA-deficient transgenic mice. Brain Res 771: 163-166.

46. Kitahama K, Maeda T, Denney RM, Jouvet M (1994) Monoamine oxidase: distribution in the cat brain studied by enzyme- and immunohistochemistry: Recent progress. Prog Neurobiol 42: 53-78.

47. Yang HY, Neff NH (1973) Beta-phenylethylamine: a specific substrate for type B monoamine oxidase of brain. J Pharmacol Exp Ther 187: 365-371.

48. Arai R, Horiike K, Hasegawa Y (1998) Dopamine-degrading activity of monoamine oxidase in locus coeruleus and dorsal raphe nucleus neurons. $A$ histochemical study in the rat. Neurosci Lett 26: 41-44.

49. Sved AF (1990) Effects of monoamine oxidase inhibition on catecholamine levels: evidence for synthesis but not storage of epinephrine in rat spinal cord. Brain Res 512: 253-258.

50. Pau KY, Ma YJ, Yu JH, Yang SP, Airhart N, et al. (1997) Topographic comparison of the expression of norepinephrine transporter, tyrosine hydroxylase and neuropeptide $Y$ mRNA in association with dopamine beta-hydroxylase neurons in the rabbit brainstem. Brain Res Mol Brain Res 48: 367-381.

51. Westlund KN, Denney RM, Kochersperger LM, Rose RM, Abell CW (1985) Distinct monoamine oxidase $A$ and $B$ populations in primate brain. Science 230 : 181-183.

52. Westlund KN, Denney RM, Rose RM, Abell CW (1988) Localization of distinct monoamine oxidase $A$ and monoamine oxidase $B$ cell populations in human brainstem. Neuroscience 25: 439-456.

53. Kitahama K, Bérod A, Denoyer M, Jouvet M (1987) Visualization of tyrosine hydroxylase-immunoreactive neurons in the cat dorsal motor vagal cells after treatment with parachlorophenylalanine. Neurosci Lett 77: 155-160.

54. Kitahama K, Denney RM, Maeda T, Jouvet M (1991) Distribution of type B monoamine oxidase immunoreactivity in the cat brain with reference to enzyme histochemistry. Neuroscience 44: 185-204.

55. Reader TA, Brière R, Grondin L, Ferron A(1986) Effects of p-chlorophenylalanine on cortical monoamines and on the activity of noradrenergic neurons Neurochem Res 11: 1025-1035.

56. Nagatsu t, Levitt M, Udenfriend S (1964) Tyrosine Hydroxylase. The initial step in norepinephrine biosynthesis. J Biol Chem 239: 2910-2917.

57. Koed K, Linnet K (2000) Opposing changes in serotonin and norepinephrine transporter mRNA levels after serotonin depletion. Eur. Neuropsychopharmaco 10: $501-509$

58. Olson EB, Dempsey JA, McCrimmon DR (1979) Serotonin and the control of ventilation in awake rats. $\mathrm{J}$ Clin Invest 64: 689-693.

59. Chiba T, Kato M (1978) Synaptic structures and quantification of catecholaminergic axons in the nucleus tractus solitarius of the rat: possible modulatory roles of catecholamines in baroreceptor reflexes. Brain Res 151 : 323-338.

60. Shapiro RE, Miselis RR (1985) The central neural connections of the area postrema of the rat. J Comp Neurol 234: 344-364.

61. Rukhadze I, Kubin L (2007) Differential pontomedullary catecholaminergic projections to hypoglossal motor nucleus and viscerosensory nucleus of the solitary tract. J Chem Neuroanat 33: 23-33.

62. Ricardo JA, Koh ET (1978) Anatomical evidence of direct projections from the nucleus of the solitary tract to the hypothalamus, amygdala, and other forebrain structures in the rat. Brain Res 153: 1-26.

63. Ter Horst GJ, de Boer P, Luiten PG, van Willigen JD (1989) Ascending projections from the solitary tract nucleus to the hypothalamus. A Phaseolus vulgaris lectin tracing study in the rat. Neuroscience 31: 785-797.

64. Dassesse D, Hemmens B, Cuvelier L, Résibois A (1997) GTP-cyclohydrolaselike immunoreactivity in rat brain. Brain Res 777: 187-201.

65. Levin BE (1979) The use of neurotoxins to characterize the rates and subcellular distributions of axonally transported dopamine-beta-hydroxylase, tyrosine hydroxylase and norepinephrine in the rat brain. Brain Res 168: 331-350.

66. Fuxe K, Hökfelt T, Ritzen M, Ungerstedt U (1968) Studies on uptake of intraventricularly administered tritiated noradrenaline and 5-hydoxytryptamine with combined fluorescence histochemical and autoradiographic technics. Histochemie 16: 186-194

67. Fuxe K, Ungerstedt $U$ (1968) Histochemical studies on the distribution of catecholamines and 5-hydroxytryptamine after intraventricular injections. Histochemie 13: 16-28.

68. Sotelo C (1971) The fine structural localization of norepinephrine- $3 \mathrm{H}$ in the substantia nigra and area postrema of the rat. An autoradiographic study. $J$ Ultrastruct Res 36: 824-841.

69. Lorang D, Amara SG, Simerly RB (1994) Cell-type-specific expression of catecholamine transporters in the rat brain. J Neurosci 14: 4903-4914.

70. Torack RM, Stranahan P, Hartman BK (1973a) The role of norepinephrine in the function of the area postrema. I. Immunofluorescent localization of dopaminebeta-hydroxylase and electron microscopy. Brain Res 61: 235-252.

71. Torack RM, LaValle M (1973b) The role of norepinephrine in the function of the area postrema. II. In vitro incubation and stimulated release of tritiated norepinephrine. Brain Res 61: 253-265.

72. Bianchi AL, Denavit-Saubié M, Champagnat J (1995) Central contro of breathing in mammals: neuronal circuitry, membrane properties, and neurotransmitters. Physiol Rev 75: 1-45

73. Ellenberger HH, Vera PL, Haselton JR, Haselton CL, Schneiderman N (1990) Brainstem projections to the phrenic nucleus: an anterograde and retrograde HRP study in the rabbit. Brain Res Bull 24: 163-174.

74. Pilowsky PM, Jiang C, Lipski J (1990) An intracellular study of respiratory neurons in the rostral ventrolateral medulla of the rat and their relationship to catecholamine-containing neurons. J Comp Neurol 301: 604-617.

75. Champagnat J, Denavit-Saubié M, Henry JL, Leviel V (1979) Catecholaminergic depressant effects on bulbar respiratory mechanisms. Brain Res 160: 57-68.

76. Viemari JC, Ramirez JM (2006) Norepinephrine differentially modulates different types of respiratory pacemaker and nonpacemaker neurons. J Neurophysiol 95: 2070-2082.

77. Soulier V, Cottet-Emard JM, Pequignot J, Hanchin F, Peyrin L, et al. (1992) Differential effects of long-term hypoxia on norepinephrine turnover in brain stem cell groups. J Appl Physiol (1985) 73: 1810-1814.

78. Dumas S, Pequignot JM, Ghilini G, Mallet J, Denavit-Saubie M (1996) Plasticity of tyrosine hydroxylase gene expression in the rat nucleus tractus solitarius after ventilatory acclimatization to hypoxia. Brain Res Mol Brain Res 40: 188194

79. Soulier V, Cottet-Emard JM, Dalmaz Y, Kitahama K, Pequignot JM (1995) Delayed increase of tyrosine hydroxylation in the rat A2 medullary neurons upon long-term hypoxia. Brain Res 674: 188-195.

80. Schmitt P, Soulier V, Péquignot JM, Pujol JF, Denavit-Saubié M (1994) Ventilatory acclimatization to chronic hypoxia: relationship to noradrenaline metabolism in the rat solitary complex. J Physiol $477: 331-337$.

81. Pascual O, Denavit-Saubie M, Dumas S, Kietzmann T, Ghilini G, et al. (2001) Selective cardiorespiratory and catecholaminergic areas express the hypoxiainducible factor-1alpha (HIF-1a) under in vivo hypoxia in rat brainstem. Eur Neurosci 14: 1981-1991.

2. Semenza GL (2004) Intratumoral hypoxia, radiation resistance, and HIF-1. Cancer Cell 5: 405-406.

83. Schnell PO, Ignacak ML, Bauer AL, Striet JB, Paulding WR, et al. (2003) Regulation of tyrosine hydroxylase promoter activity by the von HippelLindau tumor suppressor protein and hypoxia-inducible transcription factors. $J$ Neurochem 85: 483-491.

84. Haxhiu MA, Yung K, Erokwu B, Cherniack NS (1996) CO2-induced c-fos expression in the CNS catecholaminergic neurons. Respir Physiol 105: 35-45

85. Bhargava KP, Mishra N, Tangri KK (1972) An analysis of central adrenoceptors for control of cardiovascular function. Br J Pharmacol 45: 596-602.

86. Doba N, Reis DJ (1972) Localization within the lower brainstem of a receptive area mediating the pressor response to increased intracranial pressure (the Cushing response). Brain Res 47: 487-491.

87. Zandberg P, Palkovits M, De Jong W (1978) Effect of various lesions in the nucleus tractus solitarii of the rat on blood pressure, heart rate and cardiovascular reflex responses. Clin Exp Hypertens 1: 355-379. 
Citation: Ikemoto K, Geffard M, Tillet Y, Kitahama K (2015) Noradrenaline-Immunoreactive Neuronal Structures in the Cat Dorsal Vagal Complex: Interaction with Pargyline, Parachlorophenylalanine or Colchicine Pretreatment. J Neurol Neurophysiol 6: 334. doi:10.4172/21559562.1000334

Page 15 of 15

88. DeJong W, Petty M (1982) Chemical stimulation of the nucleus of the solitary tract and the resulting blood pressure response. J Cardiovasc Pharmacol 4: S77-S80.

89. Zandberg P, De Jong W, De Wied D (1979) Effect of catecholamine-receptor stimulating agents on blood pressure after local application in the nucleus tractus solitarii of the medulla oblongata. Eur J Pharmacol 55: 43-56.

90. Klausmair A, Singewald N, Philippu A (1991) Release of endogenous catecholamines in two different regions of the nucleus of the solitary tract as influenced by carotid occlusion. Naunyn. Schmiedebergs. Arch Pharmacol 343 . $155-160$.

91. Philippu A, Pfitscher A, Singewald N (1991) Involvement of catecholaminergic neurones of the nucleus of the solitary tract (NTS) in blood pressure regulation J Neural Transm Suppl 34: 107-112.

92. Sumal KK, Blessing WW, Joh TH, Reis DJ, Pickel VM (1983) Synaptic interaction of vagal afferents and catecholaminergic neurons in the rat nucleus tractus solitarius. Brain Res 277: 31-40.

93. Gieroba ZJ, Blessing WW (1994) Fos-containing neurons in medulla and pons after unilateral stimulation of the afferent abdominal vagus in conscious rabbits. Neuroscience 59: 851-858.

94. Rogers RC, Travagli RA, Hermann GE (2003) Noradrenergic neurons in the rat solitary nucleus participate in the esophageal-gastric relaxation reflex. Am J Physiol Regul Integr Comp Physiol 285: 479-489.

95. Reyes BA, Van Bockstaele EJ (2006) Divergent projections of catecholaminergic neurons in the nucleus of the solitary tract to limbic forebrain and medullary autonomic brain regions. Brain Res 1117: 69-79.

96. Onaka T, Luckman SM, Antonijevic I, Palmer JR, Leng G (1995) Involvement of the noradrenergic afferents from the nucleus tractus solitarii to the supraoptic nucleus in oxytocin release after peripheral cholecystokinin octapeptide in the rat. Neuroscience 66: 403-412.

97. Yang M, Zhao X, Miselis RR (1999) The origin of catecholaminergic nerve fibers in the subdiaphragmatic vagus nerve of rat. J Auton Nerv Syst 76: 108-117.
98. Kalia M, Mesulam MM (1980a) Brain stem projections of sensory and motor components of the vagus complex in the cat: II. Laryngeal, tracheobronchial pulmonary, cardiac, and gastrointestinal branches. J Comp Neurol 193: 467508

99. Kalia M, Mesulam MM (1980b) Brain stem projections of sensory and moto components of the vagal complex in the cat. I. The cervical vagus and nodose ganglion. J Comp Neurol 193: 435-465.

100. Miceli MO, Malsbury CW (1985) Brainstem origins and projections of the cervical and abdominal vagus in the golden hamster: a horseradish peroxidase study. J Comp Neurol 237: 65-76.

101. Unnerstall JR, Kopajtic TA, Kuhar MJ (1984) Distribution of alpha 2 agonis binding sites in the rat and human central nervous system: analysis of some functional, anatomic correlates of the pharmacologic effects of clonidine and related adrenergic agents. Brain Res 319: 69-101.

102. Palacios J, Wamsley J (1984) Catecholamine receptors. In: Borklund, A. Hökfelt, T. and Kuhar, M. J. (eds) Handbook of Chemical Neuroanatomy Vol.3. Elsevier Amsterdam 325-351.

103. Akiyama T and Yamazaki T (2000) Adrenergic inhibition of endogenous acetylcholine release on postganglionic cardiac vagal nerve terminals. Cardiovasc Res 46: 531-538.

104. Siaud P, Mekaouche M, Givalois L, Balmefrezol M, Marcilhac A, et al. (1995) Effects of pharmacological lesion of adrenergic innervation of the dorsal vagal nucleus on pancreatic insulin secretion in normal and vagotomized rats. Physiol Res 44: 227-231.

105. Jouvet M (1972) The role of monoamines and acetylcholine-containing neurons in the regulation of the sleep-waking cycle. Ergeb Physiol 64: 166307.

106. Hobson JA, Datta S, Calvo JM, Quattrochi J (1993) Acetylcholine as a brain state modulator: triggering and long-term regulation of REM sleep. Prog Brain Res 98: 389-404. 